\title{
Key elements of high-quality practice organisation in primary health care: a systematic review
}

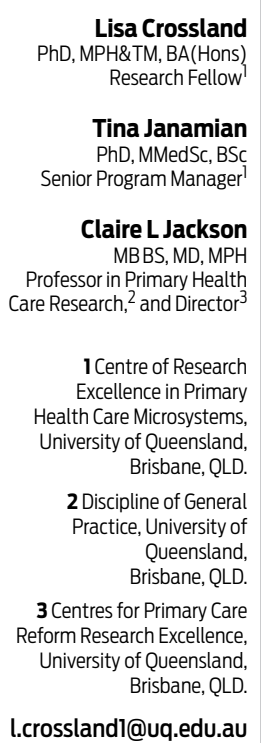

doi: 10.5694/mjal4.00305

Online first 21/07/14

\section{T} here has been a growing international evolution of the role and purpose of quality improvement in primary care; particularly in the United Kingdom, Europe, Australia and New Zealand. Research has focused on improving clinical care programs, with a corresponding focus on the identification and development of clinical measures and indicators of quality care. Subsequently, attention has been given to the role of clinical governance in the delivery of high-quality care in general practice, and exploration of the relationship between clinical management and patient health outcomes. ${ }^{1-5}$

The past 12 years also witnessed an international movement from funders paying for activity to paying for outcomes. The UK introduced "pay for performance" in 2002, resulting in general practices receiving up to $25 \%$ of their funding from measuring and reporting against 134 quality benchmarks. ${ }^{6}$ The United States debated options including significant bundled payments to family practitioners for quality targets. ${ }^{7}$ New Zealand developed a framework to guide clinical quality in primary care. ${ }^{8}$ Australia's quality measures, including the Practice Incentives Program and Service Incentive Payments, were introduced in 2002, but their funding has been progressively decreased over recent years. The Royal Australian College of General Practitioners standards form the basis of Australian general practice accreditation, and include elements such as infrastructure and clinical management. ${ }^{9}$

There is a growing international consensus regarding the impact of organisational elements on the delivery of highquality care and as enablers of successful continuous quality improvement. ${ }^{10-12}$ Elements include leadership; practical and human resources; active engagement of all staff; and attention to multifaceted interventions and coordinated action at all levels of the health system, such as investment in training and development of robust and timely data through supported information technology. ${ }^{13-15}$ The relationship between practice assessment, organisational development and assessment, and quality improvement is complicated. An understanding of the elements of highperforming practices may contribute to the development of organisational and cultural assessment processes, which in turn lead to organisational development relevant to primary care as part of the broader concept of successful continuous quality improvement. Conversely, undertaking successful continuous quality improvement through activities associated with organisational development and using organisational assessment approaches may, in turn, indicate elements integral to high-quality practice performance (Box 1). Indeed, there is dearth of evidence related to the impact of organisational components of general practice and patient outcomes. ${ }^{16}$

In this article, we sought to identify elements, contained in the literature, which have been demonstrated as integral to high-quality practice performance. For the purpose of

\section{Abstract \\ Objectives: To identify elements that are integral to high- quality practice and determine considerations relating to high-quality practice organisation in primary care.}

Study design: A narrative systematic review of published and grey literature.

Data sources: Electronic databases (PubMed, CINAHL, the Cochrane Library, Embase, Emerald Insight, Psyclnfo, the Primary Health Care Research and Information Service website, Google Scholar) were searched in November 2013 and used to identify articles published in English from 2002 to 2013. Reference lists of included articles were searched for relevant unpublished articles and reports.

Data synthesis: Data were configured at the study level to allow for the inclusion of findings from a broad range of study types. Ten elements were most often included in the existing organisational assessment tools. A further three elements were identified from an inductive thematic analysis of descriptive articles, and were noted as important considerations in effective quality improvement in primary care settings.

Conclusion: Although there are some validated tools available to primary care that identify and build quality, most are single-strategy approaches developed outside health care settings. There are currently no validated organisational improvement tools, designed specifically for primary health care, which combine all elements of practice improvement and whose use does not require extensive external facilitation.

this study, practice organisation was defined as "'systems, structures and processes aimed to enable the delivery of good quality patient care', excluding clinical processes and clinical outcomes". 17

We defined the term tools as surveys, questionnaires or assessment instruments designed to measure overall or specific elements related to practice organisation, as defined above.

\section{Methods}

We undertook a narrative systematic literature review. The specific questions addressed were:

- What elements (attributes or characteristics) are integral to high-quality primary care practice organisation?

- What are the current key considerations relating to organisational performance in primary care?

Key methods are summarised below; full details can be found in Appendix 1 (online at mja.com.au).

We searched several electronic databases: PubMed, the Cochrane Library, CINAHL, Embase, Emerald Insight, PsycInfo, the Primary Health Care Research and Information Service (PHCRIS) website and Google Scholar. Additional articles and reports were identified through the reference lists of all reviewed studies. A complete 


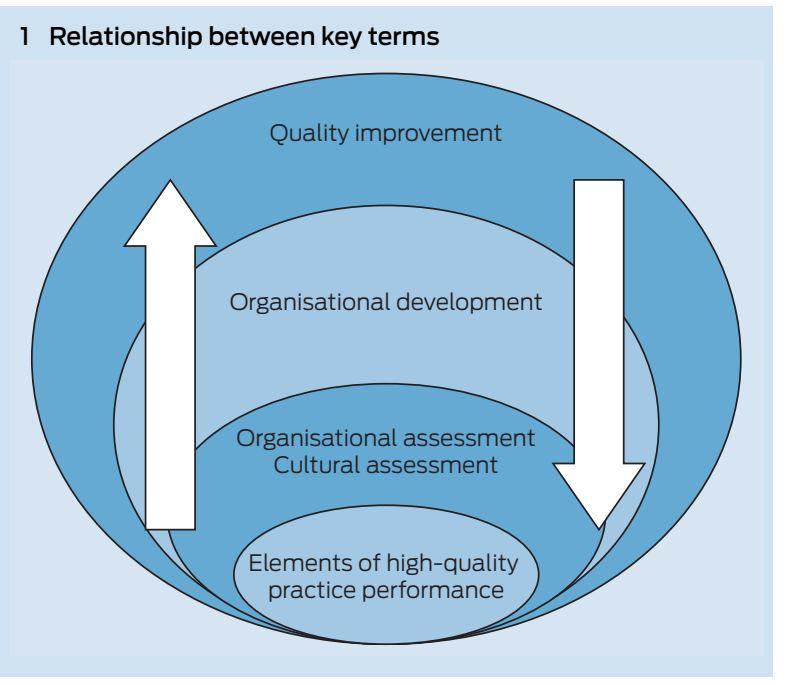

description of the search strategy, including search terms and study eligibility criteria, is found in Appendix 2 (online at mja.com.au).

Data were extracted from eligible articles and reports using a data extraction form guided by the template used by Dunbar and colleagues. ${ }^{18}$

A qualitative inductive thematic approach was used to explore the discussion sections of all articles (surveys; trials; frameworks, models or approaches to organisational improvement or assessment) to explore information about the application and perceived impacts of tools and frameworks. Incorporating this information added further clarification,

\section{Flow diagram depicting selection process of studies for analysis}

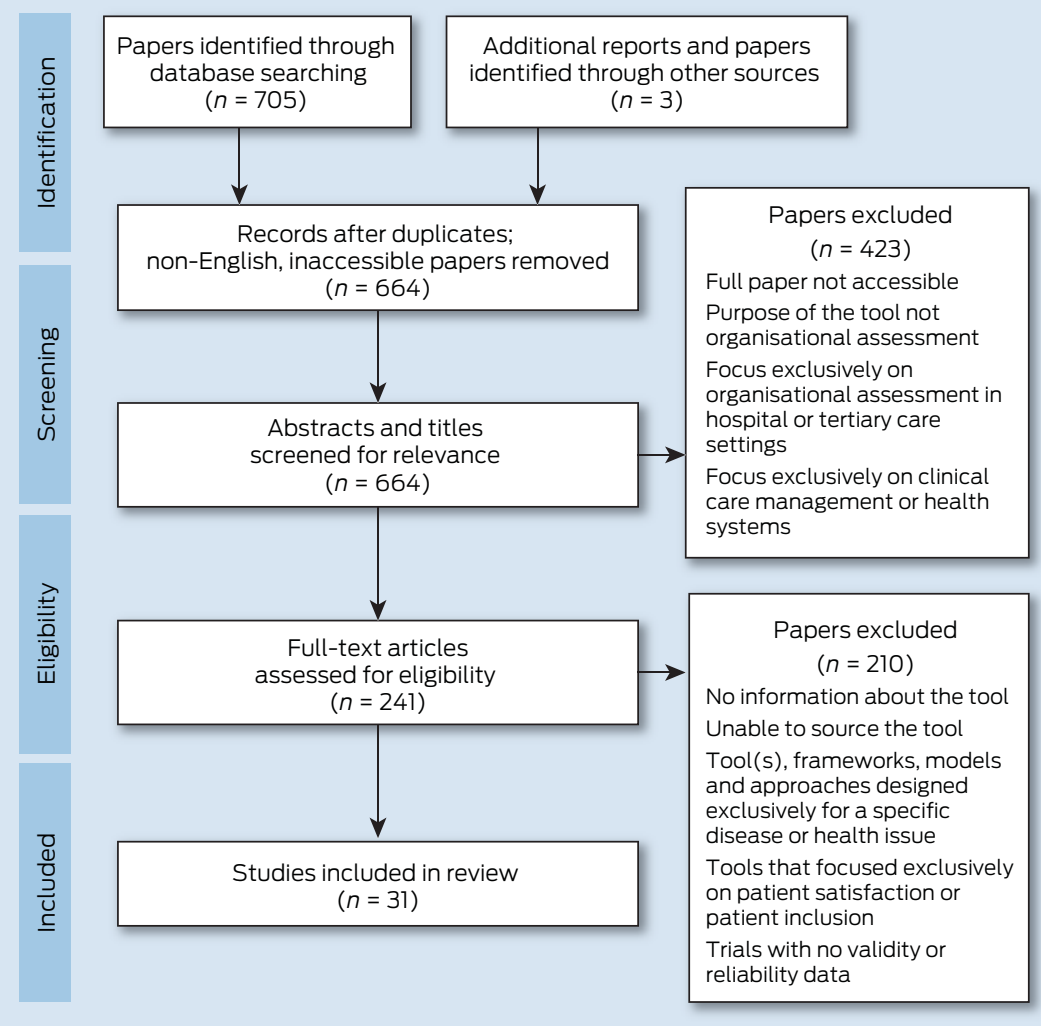

particularly of the relevance of identified elements to general practice settings.

Data were configured at the study level to allow for the inclusion of findings from a broad range of study types (systematic literature reviews, trials, frameworks, descriptive, knowledge-building papers and key informant discussions). Results were compared and combined to identify the elements of organisational assessment in primary health care that are integral to high-quality practice performance.

\section{Results}

A total of 241 manuscripts were obtained for review. Of these, 210 manuscripts were excluded due to no or insufficient information about the tool and elements of practice performance. Tools that focused on elements of patient safety (eg, the Frankfurt Patient Safety Climate Questionnaire for General Practices; the UK National Health Service [NHS] Manchester Patient Safety Framework - Primary Care; NHS Education for Scotland's SafeQuest) or on the developing patient role in health care decision making (including the General Practice Assessment Questionnaire and Europep) were excluded from data extraction. ${ }^{19-25} \mathrm{~A}$ full description of the systematic review screening process is presented in Box 2.

All citations were imported to Endnote. A total of 31 articles were included for data extraction, including one systematic review; 25 developmental trials or surveys of organisational assessment and tools or guides and six descriptive articles or reports. Of these, three were Australian; 13 were from the US; 14 from the UK and Europe; and two were Canadian. These articles included information on 10 organisational assessment tools or methods.

\section{Elements identified as integral to high-quality practice performance}

We identified 10 elements that were integral to high-quality organisational performance in general practice. Appendix 3 (online at mja.com.au) lists these elements according to the tools that include them. It should be noted that this table highlights elements that were specifically contained in the tools. However it should also be noted that several externally facilitated tools could draw out broader issues in practice management during facilitation.

The following 10 elements were most frequently included in existing organisational assessment tools:

Patient-centred approaches: This element included tailoring service delivery to the context of family and the broader local community; the importance of a community focus; use of community resources; and cultural competence in relation to a knowledge and understanding of the local community the practice serves.

Leadership and leading: This included the concepts of knowledge of, and attitudes to, practice leaders in practice organisation, administration and clinical care. The element also related to individual practice members who may lead in relation to innovation and change; it addressed concepts of effective leadership and "leading" behaviours, regardless of individual positions and roles. 
Focus on staff: This element contained the concepts of staff satisfaction, autonomy, skills and professionalism. It also addressed monitoring of staff workloads and job stresses.

Clinical governance: Closely associated with the element of communication and collaboration, the element of clinical governance related to the formal systems and structures in place to ensure effective care delivery and clinical safety, such as patient complaints procedures; patient call-back processes and medicine alerts; with a specific emphasis on clinical care structures and risk management.

Multiprofessional teams: This element contained concepts of the ease of forming multiprofessional teams in practice; effective teamwork in relation to important diseases; and relationships between clinical and non-clinical staff, including understanding each other's roles and the ability to learn through conflict.

Communication: This element encompassed a range of concepts - formal and informal processes of communication internal to the practice, including delegation; environmental and cultural factors that support effective collaboration and linkage between the practice and outside services; methods of timely referral; and sharing of patient information. It also encompassed environmental factors that supported sharing information with patients.

Education and training: This element was seen as a fundamentally important part of quality improvement. It relates to provision of, and access to, appropriate training for staff, as part of existing roles. It also included education and training tailored to changes undertaken in the practice.

Process improvement: Closely linked to the element of performance results, this element also most commonly related to clinical processes of care, the systems in place for monitoring the process of practice health care delivery, and internal improvements to the practice.

Performance results: This encompassed processes to support reporting of results of performance measures internally and externally. It included benchmarking against other services.

Information and information technology: Finally, the use of information and information technology included aspects such as the effective collection and use of information and the effective use of technology (eg, practice clinical software). This element most commonly focused on the use of patient clinical information, less common was the inclusion of information and data on practice finances and billing, and data related to human resource management. It also encompassed the sharing of patient clinical information internally, and between the practice and external services.

Three less commonly included characteristics were identified from the discussion sections of descriptive articles and trials of some tools. During the inductive thematic review, phrases were grouped into the most commonly occurring themes or attributes associated with high-quality practice performance, namely:

Incentives and rewards: This attribute included the capacity for all staff to receive recognition and reward for their work - not just financially, but also in recognition from peers, ability to attend conferences or join professional groups. Financial incentives as part of organisational development facilitated and sustained effective team-based approaches to care. However, this element was not specifically included in existing tools but was linked to discussions in organisational governance and change management.

Organisational governance: This element included the definition of a shared direction, mission and values; strategic planning and implementation; and collection and inclusion of administrative data.

Change and change management: This attribute included the ability, willingness and flexibility of the practice staff to adapt to new standards and procedures; the ability and willingness of the practice staff to make, manage and sustain change. A practice with a history of change was also identified as an important structural part of successful and ongoing performance improvement.

\section{Synthesis of results}

Combined, these 13 elements represent the characteristics of organisational context that are integral to high-performing practices (Box 3). Rather than being discrete elements, they are also interlinked. For example, the element of communication - information availability, defined as the sharing and communication of information internally and externally, is closely linked to the development of multiprofessional team-based care approaches. The element of education and training for all staff and incentives is integral to successful change management and ongoing readiness for change.

\section{Discussion}

Most existing quality improvement tools are designed for tertiary care settings or for non-health care organisations. ${ }^{5}$ Those developed for general practice and primary health care are single strategies such as audit, professional education (continuing medical education) and frameworks for patient safety and risk management. A review of organisational assessment tools used in the UK concluded that while externally led quality improvement approaches, such as accreditation, are reasonably well developed, internally led approaches are much less so. ${ }^{46}$

There are several considerations relating to organisational performance. First, a primary health care tool should define elements essential to primary health care, be sensitive to clinical management, enable the users to better understand their own practice context, and include staff in the process of identifying and addressing improvement activities of relevance. Second, as health care delivery becomes more complex and technology-driven, the organisational context in which qualitative improvement initiatives take place becomes a crucial determinant of their effectiveness. ${ }^{10,11}$ Research on primary care practice development identified these contextual elements as "adaptive reserves", or features that represent a practice's internal capability. ${ }^{47}$ Finally, many of the elements identified here are also organisational attributes that enable the success of practice-based improvement initiatives. ${ }^{13}$ Thus, the challenges are to develop a tool bespoke to primary care with a whole-of-practice approach; that can fit a wide range of contexts; that is relevant to the clinical management aspects of general practice and effectively takes into account organisational aspects of care; that includes elements relating to organisational culture; 


\begin{tabular}{|c|c|c|c|}
\hline Element & Source & Association between elements & References \\
\hline Patient-centred care & $\begin{array}{l}\text { Development of a tool; multisite trials of existing } \\
\text { tools; research article }\end{array}$ & $\begin{array}{l}\text { Linked to clinical governance and team-based } \\
\text { care }\end{array}$ & $\begin{array}{l}26,27,28,29,30,31,32,33 \\
34,35,36\end{array}$ \\
\hline Leadership and leading & Multisite trial of existing tool; descriptive framework & $\begin{array}{l}\text { Linked to organisational governance, } \\
\text { team-based care; communication; process } \\
\text { improvement and performance results }\end{array}$ & $28,29,30,37,31,32,33,38,39$ \\
\hline Focus on staff & Multisite trial of existing tool; descriptive framework & $\begin{array}{l}\text { Linked to leadership and organisational } \\
\text { governance }\end{array}$ & $\begin{array}{l}40,41,26,27,28,29,32,37,31 \\
32,34,35,38,39\end{array}$ \\
\hline Clinical governance & $\begin{array}{l}\text { Development of a tool; multisite trial of existing tool; } \\
\text { research article }\end{array}$ & Linked to team-based care & $9,29,30,34,35,42,38,39,36$ \\
\hline Multiprofessional teams & $\begin{array}{l}\text { Development of tools; multisite trial of existing tools; } \\
\text { research article }\end{array}$ & $\begin{array}{l}\text { Linked to communication and patient-centred } \\
\text { care }\end{array}$ & $\begin{array}{l}28,29,30,43,33,34,35,38 \\
39,36\end{array}$ \\
\hline Communication & Descriptive framework & $\begin{array}{l}\text { Linked to collaborative and integrated } \\
\text { approaches to care; team-based care }\end{array}$ & $9,40,41,28,29,30,38,39$ \\
\hline Education and training & Multisite trial of existing tools; descriptive framework & Linked to change management & $9,27,28,29,34,35,42$ \\
\hline Process improvement & Multisite trial of existing tool; descriptive framework & Linked to performance results & $28,29,43,37,31,32,34,35$ \\
\hline Performance results & Multisite trial of existing tool; descriptive framework & $\begin{array}{l}\text { Linked to element of information and } \\
\text { information technology }\end{array}$ & $28,29,37,31,32,35,42,29,44$ \\
\hline $\begin{array}{l}\text { Information and information } \\
\text { technology }\end{array}$ & $\begin{array}{l}\text { Development of tool; multisite trial of existing tool; } \\
\text { research paper to identify attributes }\end{array}$ & $\begin{array}{l}\text { Linked to clinical governance; process } \\
\text { improvement and performance results }\end{array}$ & $9,40,28,29,34,35,36$ \\
\hline Incentives and rewards & Descriptive framework & Linked to change management & 45,46 \\
\hline Organisational governance & $\begin{array}{l}\text { Multisite trial of existing tool; descriptive framework; } \\
\text { descriptions of cultural diagnostic tools }\end{array}$ & Linked to leadership and change management & $9,47,48$ \\
\hline $\begin{array}{l}\text { Change and change } \\
\text { management }\end{array}$ & Descriptive framework & $\begin{array}{l}\text { Linked to leadership, education and training, } \\
\text { process improvement, performance results and } \\
\text { incentives }\end{array}$ & $38,39,36,48$ \\
\hline
\end{tabular}

that is low or no cost; and that can be used effectively as part of an internally led quality improvement process.

The literature in relation to quality improvement is large and diverse; however, studies relating specifically to practice management performance are poorly defined in relation to specific search terms. We deliberately used broad search terms to capture the totality of elements, domains and characteristics included across all tools, frameworks, models and approaches.

There are presently no validated organisational improvement tools, designed specifically for primary care, which can be used internally in a best-practice approach that facilitates both organisational improvement and also raises awareness about the present culture of a practice. Based on the findings from this systematic review, we have now undertaken the development and pilot of a new internally led Primary Care Practice Improvement Tool (PC-PIT), incorporating the elements identified here. ${ }^{49} \mathrm{~A}$ national trial is now underway, and future work will explore the link between improved organisational performance and patient outcomes at the practice level. With the continued focus on the important place of general practice and primary health care in the broader health care context, and a refocus on the importance of organisational aspects of practice in relation to quality care delivery, the time is now right to focus on a standardised internally led approach to improving practice performance, designed for the dynamic context of primary health care.

Acknowledgements: We acknowledge funding provided through the Australian Primary Health Care Research Institute.

Competing interests: No relevant disclosures.

Provenance: Commissioned; externally peer reviewed.
1 Scally G, Donaldson LJ. The NHS's 50 anniversary. Clinical governance and the drive for quality improvement in the new NHS in England. BMJ 1998; 317: 61-65.

2 Buetow SA, Roland M. Clinical governance: bridging the gap between the managerial and clinical approaches to quality of care. Qual Health Care 1999; 8: 184-190.

3 Seddon ME, Marshall MN, Campbell SM, Roland MO. Systematic review of studies of quality of clinical care in general practice in the UK, Australia and New Zealand. Qual Health Care 2001; 10: 152-158.

4 Campbell SM, Sweeney GM. The role of clinical governance as a strategy for quality improvement in primary care. Br J Gen Pract 2002; 52 Suppl: S12-S17.

5 Phillips CB, Pearce CM, Hall S, et al. Can clinical governance deliver quality improvement in Australian general practice and primary care? A systematic review of the evidence. Med J Aust 2010; 193: 602-607.

6 Roland M. Linking physicians' pay to quality of care - a major experiment in the United Kingdom. N Engl J Med 2004; 351: 1448-1454.

7 Berenson RA, Rich EC. US approaches to physician payment: the deconstruction of primary care. J Gen Intern Med 2010; 25: 613-618.

8 Perera GA, Dowell AC, Morris CJ. Constructing a framework for quality activity in primary care. Aust Health Rev 2013; 37: 98-103.

9 Royal Australian College of General Practitioners. Standards for general practices. 4th ed. South Melbourne: RACGP, 2010. http://www.racgp.org.au/ your-practice/standards/standards4thedition (accessed Jun 2014).

10 Walshe K, Freeman T. Effectiveness of quality improvement: learning from evaluations. Qual Saf Health Care 2002; 11: 85-87.

11 Engels Y, Campbell S, Dautzenberg M, et al. Developing a framework of, and quality indicators for, general practice management in Europe. Fam Pract 2005; 22: 215-222.

12 Sloane PD, Wroth T, Halladay J, et al. How eight primary care practices initiated and maintained quality monitoring and reporting. J Am Board Fam Med 2011; 24: 360-369.

13 Brennan SE, Bosch M, Buchan H, Green SE. Measuring organizational and individual factors thought to influence the success of quality improvement in primary care: a systematic review of instruments. Implement Sci 2012; 7: 121.

14 Flottorp SA, Oxman AD, Krause J, et al. A checklist for identifying determinants of practice: a systematic review and synthesis of frameworks and taxonomies of factors that prevent or enable improvements in health care professional practice. Implement Sci 2013; 8: 35.

15 Powell AE, Rushmer RK, Davies HT. A systematic narrative review of quality improvement models in health care. Glasgow: National Health Service Quality Improvement Scotland, 2009. http://www. 
healthcareimprovementscotland.org/previous_resources/hta_report/ health_care_improvement_models.aspx (accessed Jun 2014).

16 Hinchcliff R, Boxall AM, Partel KH, et al. Accreditation of health services: is it money and time well spent? Evidence brief no. 9. Canberra: Deeble Institute, Australian Hospitals and Healthcare Association, 2013. http:// ahha.asn.au/sites/default/files/publication/17471/20130411_deeble_ institute_evidence_brief_accreditation_of_health_services.pdf (accessed Jun 2014).

17 Engels Y, Dautzenberg M, Campbell S, et al. Testing a European set of indicators for the evaluation of the management of primary care practices. Fam Pract 2006; 23: 137-147.

18 Dunbar JA, Reddy P, McAvoy B, et al. The contribution of approaches to organisational change in optimising the primary health care workforce. Canberra: Australian Primary Health Care Research Institute, 2007.

19 Hoffman B, Domanska OM, Albay Z, et al. The Frankfurt Patient Safety Climate Questionnaire for General Practices (FraSik): analysis of psychometric properties. BMJ Qual Saf 2011; 20: 797-805.

20 National Primary Care and Research Development Centre. Manchester Patient Safety Framework (MaPSaF) -- primary care. Manchester: NPCRDC, University of Manchester, 2005. http://www.population-health manchester.ac.uk/primarycare/npcrdc-archive/Publications/ACFDO2.pdf (accessed Jun 2014).

21 Sexton JB, Helmreich RL, Neilands TB, et al. The Safety Attitudes Questionnaire: psychometric properties, benchmarking data, and emerging research. BMC Health Serv Res 2006; 6: 44

22 Hutchinson A, Cooper KL, Dean JE, et al. Use of a safety climate questionnaire in UK health care: factor structure, reliability and usability. Qual Saf Health Care 2006; 15: 347-353.

23 de Wet C, Spence W, Mash R, et al. The development and psychometric evaluation of a safety climate measure for primary care. Qual Saf Health Care 2010; 19: 578-584.

24 Mead N, Bower P, Roland M. The General Practice Assessment Questionnaire (GPAQ) - development and psychometric characteristics. BMC Fam Pract 2008; 9: 13.

25 Bjertnaes OA, Lyngstad I, Malterud K, Garratt A. The Norwegian EUROPEP questionnaire for patient evaluation of general practice: data quality, reliability and construct validity. Fam Pract 2011; 28: 342-349.

26 Crabtree BF, Miller WL, Stange KC. Understanding practice from the ground up. J Fam Pract 2001; 50: 881-887.

27 Kairys JA, Oranzo J, Gregory P, et al. Assessing diversity and quality in primary care through the multimethod assessment process (MAP). Qual Manag Health Care 2002; 10: 1-14.

28 Nelson EC, Batalden PB, Huber TP, et al. Microsystems in health care: Part 1. Learning from high-performing front-line clinical units. Jt Comm J Qual Improv 2002; 28: 472-493.

29 Jukkala AM, Patrician PA, Northern A, Block V. Readability and usefulness of the clinical microsystem assessment tool. J Nurs Care Qual 2011; 26: 186-191.

30 Szecsenyi J, Campbell S, Broge B, et al. Effectiveness of a qualityimprovement program in improving management of primary care practices. CMAJ 2011; 183: El326-El333.

31 Gené-Badia J, Jodar-Solá G, Peguero-Rodríguez E, et al. The EFQM excellence model is useful for primary health care teams. Fam Pract 2001; 18: 407-409.

32 Jackson S, Bircher R. Transforming a run down general practice into a leading edge primary care organisation with the help of the EFQM excellence model. Int J Health Care Qual Assur Inc Leadersh Health Serv 2002; 15: 255-267.

33 Starfield B, Cassady C, Nanda J, et al. Consumer experiences and provider perceptions of the quality of primary care: implications for managed care. $J$ Fam Pract 1998; 46: 216-226.

34 Elwyn G, Bekkers MJ, Tapp L, et al. Facilitating organisational development using the group-based formative assessment and benchmarking method: design and implementation of the International Family Practice Maturity Matrix. Qual Saf Health Care 2010; 19: e48.

35 Eriksson T, Siersma VD, Løgstrup L, et al. Documenting organisational development in general practice using a group-based assessment method: the Maturity Matrix. Qual Saf Health Care 2010; 19: e37.

36 Apekey TA, McSorley G, Tilling M, Siriwardena AN. Room for improvement? Leadership, innovation culture and uptake of quality improvement methods in general practice. J Eval Clin Pract 2011; 17: 311-318.

37 Nabitz U, Klazinga N, Walburg J. The EFQM excellence model: European and Dutch experiences with the EFQM approach in health care. Int J Qual Health Care 2000; 12: 191-201.

38 Ose D, Freund T, Kunz CU, et al. Measuring organizational attributes in primary care: a validation study in Germany. J Eval Clin Pract 2010; 16: 1289-1294.

39 Cohen D, McDaniel RR Jr, Crabtree BF, et al. A practice change model for quality improvement in primary care practice. J Healthc Manag 2003; 49 : $155-168$

40 Rhydderch M, Edwards A, Elwyn G, et al. Organizational assessment in general practice: a systematic review and implications for quality improvement. J Eval Clin Pract 2005; 11: 366-378

41 van den Hombergh P, Grol R, van den Hoogen $\mathrm{HJ}$, van den Bosch WJ. Assessment of management of general practice: validation of a practice visit method. Br J Gen Pract 1998; 48: 1743-1750.

42 DeJong $D J$. Quality improvement using the Baldrige Criteria for Organizational Performance Excellence. Am J Health Syst Pharm 2009; 66 1031-1034.

43 Sylvester S. Measuring the learning practice: diagnosing the culture in general practice. Qual Prim Care 2003; 11: 29-40.

44 Ohman-Strickland PA, John Oranzo A, Nutting PA, et al. Measuring organizational attributes of primary care practices: development of a new instrument. Health Serv Res 2007; 42: 1257-1273.

45 MidCentral District Health Board. Incentives matter: successfully executing transformative change within general practice teams. Discussion paper. Palmerston North, NZ: MCDHB, 2011. http://www.midcentraldhb.govt. nz/Publications/AllPublications/Documents/IncentivesMatterAprll.pdf (accessed Jun 2014).

46 Mannion R, Konteh FH, Davies HT. Assessing organisational culture for quality and safety improvement: a national survey of tools and tool use. Qual Saf Health Care 2009; 18: 153-156.

47 Miller W, Crabtree BF, Nutting PA, et al. Primary care practice development: a relationship-centered approach. Ann Fam Med 2010; 8 Suppl 1: S68-S79.

48 Jackson C, Nicholson C. Making integrated healthcare delivery happen - a framework for success. Asia Pacific Journal of Health Management 2008; 3: 19-24.

49 Crossland LJ, Janamian T, Sheehan M, et al. Development and pilot study of the Primary Care Practice Improvement Tool (PC-PIT): an innovative approach. Med J Aust 2014; 201 (3 Suppl): S52-S55. 